\title{
Erratum
}

\section{The Barrow Ruptured Aneurysm Trial: 3-year results}

\section{Clinical article}

To The EDITOR: We appreciate the publication of our paper entitled "The Barrow Ruptured Aneurysm Trial: 3-year results. Clinical article" (J Neurosurg 119:146-157, 2013).

Recently a Letter to the Editor from Dr. Daniel J. Denis $^{1}$ alerted us to 2 errors in our paper.

1. In the Methods section of the Abstract, we originally stated:

Of the 170 patients who had been originally assigned to coiling, 64 (38\%) crossed over to clipping, whereas 4 (2\%) of

179 patients assigned to surgery crossed over to clipping.

The last word of this sentence should have been "coiling," and thus the corrected sentence is

Of the 170 patients who had been originally assigned to coiling, $64(38 \%)$ crossed over to clipping, whereas 4 (2\%) of 179 patients assigned to surgery crossed over to coiling.

2. In the legend to Table 2, we initially stated:

* Coil-coil compared to coil-clip at 3 years: $p=0.007$. Coil-clip compared to clip-clip at 3 years: $p=0.26$. Coil-coil compared to clip-clip at 3 years: $\mathrm{p}=0.0$.

The last $\mathrm{p}$ value is incorrect; it should have been 0.04 .
The corrected legend entry is thus

* Coil-coil compared to coil-clip at 3 years: $p=0.007$.

Coil-clip compared to clip-clip at 3 years: $p=0.26$. Coil-coil compared to clip-clip at 3 years: $\mathrm{p}=\mathbf{0 . 0 4}$.

We have bolded the words that have been corrected.

We apologize to the editor and readers for our errors, and we thank Dr. Denis for pointing them out. We are pleased to have the opportunity to make these corrections. The errors were corrected online as of November $29,2013$.

Cameron G. McDougall, M.D. Robert F. SPETZLer, M.D.

Felipe C. Albuquerque, M.D. JOSEPH M. ZABRAMSKI, M.D. Peter NaKaji, M.D.

Barrow Neurological Institute St. Joseph's Hospital and Medical Center Phoenix, AZ

\section{Reference}

1. Denis DJ: Crossover and clinical outcomes in the Barrow Ruptured Aneurysm Trial. J Neurosurg [epub ahead of print November 29, 2013. DOI: 10.3171/2013.8.JNS131835] (Letter)

TABLE 2: Patients with $m R S$ scores $>2$ based on actual treatment

\begin{tabular}{|c|c|c|c|c|c|c|c|c|c|}
\hline \multirow[b]{2}{*}{ Time Point } & \multirow{2}{*}{$\begin{array}{c}\text { Available for } \\
\text { Analysis }\end{array}$} & \multicolumn{2}{|c|}{$\begin{array}{c}\text { Coil-Coil }(124 / 199) \\
\text { mRS >2 }\end{array}$} & \multicolumn{2}{|c|}{$\begin{array}{c}\text { Coil-Clip (75/199) } \\
\text { mRS >2 }\end{array}$} & \multicolumn{2}{|c|}{$\begin{array}{c}\text { Clip-Clip (205/209) } \\
\text { mRS >2 }\end{array}$} & \multicolumn{2}{|c|}{$\begin{array}{c}\text { Clip-Coil }(4 / 209) \\
m R S>2\end{array}$} \\
\hline & & $n$ & $\%$ & $\mathrm{n}$ & $\%$ & $\mathrm{n}$ & $\%$ & $\mathrm{n}$ & $\%$ \\
\hline time of treatment & 408 & & & & & & & & \\
\hline discharge & 406 & $72 / 124$ & 58.1 & $55 / 74$ & 74.3 & $144 / 204$ & 70.6 & $3 / 4$ & 75.0 \\
\hline $6 \mathrm{mos}$ & 341 & $18 / 108$ & 16.7 & $22 / 63$ & 34.9 & $59 / 167$ & 35.3 & $3 / 3$ & 100.0 \\
\hline $1 \mathrm{yr}$ & 358 & $20 / 109$ & 18.4 & $22 / 65$ & 33.9 & $61 / 180$ & 33.9 & $3 / 4$ & 75.0 \\
\hline $3 \mathrm{yrs}^{*}$ & 349 & $24 / 106$ & 22.6 & $27 / 64$ & 42.2 & $60 / 175$ & 34.3 & $4 / 4$ & 100.0 \\
\hline 3 yrs-CF† & 366 & $24 / 111$ & 21.6 & $27 / 64$ & 42.2 & $60 / 184$ & 32.6 & $4 / 4$ & 100.0 \\
\hline
\end{tabular}

Please include this information when citing this paper: published online November 29, 2013; DOI: 10.3171/2013.11.JNS12683a. 